\title{
Obstrução do trato digestório em animais de companhia, atendidos em um Hospital Veterinário no ano de 2010
}

\author{
Mariana Amata Mudado ${ }^{1}$, Ricardo Junqueira Del Carlo*2, Andréa Pacheco Batista Borges ${ }^{2}$, \\ Paulo Renato dos Santos Costa ${ }^{2}$
}

\begin{abstract}
RESUMO
O objetivo deste estudo é relatar os tipos de obstrução do trato digestório, após ingestão de corpos estranhos, em animais de companhia, atendidos no Hospital Veterinário da Universidade Federal de Viçosa (HVT-UFV), durante o ano de 2010; a predisposição racial e por faixa etária; a localização da obstrução; os sintomas relacionados; os achados laboratoriais; o tratamento proposto e a evolução clínica dos pacientes. Foi observada predisposição para animais de raça pequena e de faixas etárias de até um ano e após cinco anos, com predileção pela raça Teckel. O maior número de corpos estranhos foi encontrado no estômago e intestinos, com maior gravidade e elevada taxa de mortalidade, em relação aos encontrados no esôfago. O maior período de evolução do quadro clínico, desde a observação inicial, contribuiu para maiores taxas de mortalidade. A sintomatologia clínica dos animais foi variada, mas quadros de apatia e de anorexia ocorreram na maioria dos casos. Regurgitação e vômito foram frequentes, quando a localização do corpo estranho foi esofágica ou gastrointestinal, respectivamente. Os resultados dos exames laboratoriais foram inespecíficos.
\end{abstract}

Palavras-chave: corpo estranho digestivo, gastrotomia, enterotomia.

\begin{abstract}
Digestive tract obstruction in pets attended in a Veterinary Hospital during 2010

This study aimed to examine the cases of simple, partial and complete obstructions of the digestive tract of small animals treated at the Veterinary Hospital of the Federal University of Viçosa during the year of 2010, reporting the evolution period, clinical and laboratorial changes, and the outcome of patients, as well as determining breed, sexual and age predilections. Predisposition of small breeds and ages ranging from two to twelve months and after five years was observed, with breed predilection for Teckels The largest number of foreign bodies was found in the stomach and intestines, with greater severity and higher mortality rate when compared with esophageal foreign bodies. The longest clinical course contributed to higher mortality rates. Clinical symptoms of the animals were quite diverse, but apathy and anorexia occurred in most cases. Regurgitation and vomiting were frequent when the foreign body was esophageal or gastrointestinal, respectively. The laboratory tests were nonspecific.
\end{abstract}

Key words: digestive foreign bodies, gastrotomy, enterotomy.

Recebido para publicação em 13/02/2012 e aceito em 18/06/2012.

${ }^{1}$ Médica Veterinária, Especialista. Escola de Veterinária, Universidade Federal de Minas Gerais, Avenida Antônio Carlos, 6627, Caixa Postal 567, Campus Pampulha, 30123-970, Belo Horizonte, Minas Gerais, Brasil. mariana.mudado@yahoo.com.br

${ }^{2}$ Médicos Veterinários, Doutores. Departamento de Veterinária, Universidade Federal de Viçosa, Campus Viçosa, Avenida Peter Henry Rolfs, s/n, 36570-000, Viçosa, Minas Gerais, Brasil. ricarlo@ufv.br (*autor para correspondência); andrea@ufv.br; prenato@ufv.br 


\section{INTRODUÇÃO}

O corpo estranho $(\mathrm{CE})$ pode causar obstrução em várias porções do trato digestório. As obstruções esofágicas causadas por $\mathrm{CE}$, geralmente, ocorrem em regiões em que estruturas extraesofágicas limitam a dilatação do órgão e restringem a passagem do alimento (Gianella et al., 2009). $\mathrm{O}$ alimento que não atravessa o local da obstrução acumula-se, pode ser regurgitado ou causar distensão esofágica cranial, com presença, ou não, de anorexia, secundária à dor local (Twedt, 1995; Willard, 2006a; Hedlund \& Fossum, 2007a).

Os CEs gástricos são causa de vômito quando obstruem o fluxo alimentar e quando irritam a mucosa, sendo ocasionalmente assintomáticos (Hedlund \& Fossum, 2007b). Nas obstruções proximais do lúmen do intestino delgado, existirá a probabilidade aumentada de desidratação, desequilíbrio eletrolítico e choque, resultantes principalmente do vômito persistente e da perda de secreções gástricas. Nas obstruções distais, ocorrerão graus variados de acidose metabólica e, quando parciais, a partir do jejuno distal, poderão apresentar sinais insidiosos, como anorexia, letargia, diarreia e vômito ocasional, estendendo-se por dias (Boag et al., 2005). Corpos estranhos (CEs) que assumem configuração linear são capazes de promover obstrução intestinal, após a sua fixação em um ponto que pode ser a base da língua, comum em gatos, ou o piloro, em cães, podendo causar obstrução parcial ou completa, com perfuração e peritonite (Twedt, 1995; Hayes, 2009). Os CEs que atingem o cólon, geralmente, são expelidos com as fezes, a não ser que o cólon distal ou o reto estejam obstruídos ou o objeto seja pontiagudo (Hedlund \& Fossum, 2007b).

Os CEs esofágicos e gástricos podem ser removidos por endoscopia (Gianella et al., 2009) ou cirurgicamente (Parker et al., 1989). A gastrotomia e a enterotomia são realizadas para remoção de corpo estranho causador de obstrução simples, parcial ou completa. A ressecção e anastomose de alças intestinais são utilizadas quando ocorre envolvimento vascular com isquemia e necrose de segmentos (Ellison, 1998; Fossum \& Hedlund, 2003).

Este estudo relata os tipos de obstrução do trato digestório, após ingestão de corpos estranhos, em animais de companhia atendidos no Hospital Veterinário da Universidade Federal de Viçosa (HVT-UFV), durante o ano de 2010, a predisposição racial e por faixa etária, a localização da obstrução, os sintomas relacionados, os achados laboratoriais, o tratamento proposto e a evolução clínica dos pacientes.

\section{MATERIAL E MÉTODOS}

Trata-se de um estudo retrospectivo e foram selecionados os 17 animais diagnosticados com obstrução do trato digestório por ingestão de $\mathrm{CE}$, atendidos, durante o ano de 2010, no Hospital Veterinário da Universidade Federal de Viçosa (HVT-UFV), Viçosa, Minas Gerais. Por meio das fichas de atendimento desses animais, foram coletados dados que envolveram espécie, raça, idade, sexo, procedimentos laboratoriais e cirúrgicos realizados, tipo e localização dos CEs, evolução dos sinais clínicos e desfecho dos casos. Um dos pacientes diagnosticado com $\mathrm{CE}$ esofágico não retornou ao atendimento para realização da endoscopia agendada, e, portanto, não teve computadas algumas das análises realizadas.

A evolução do quadro clínico foi considerada desde o reconhecimento dos sintomas, ou desde a ingestão sabida do CE, até a primeira apresentação do animal ao Hospital Veterinário. Em algumas análises, essa evolução foi subdividida em dois períodos: antes de sete dias e sete, ou mais, dias de apresentação dos sinais clínicos.

Os procedimentos clinicocirúrgicos relatados foram: anamnese, exame físico e, quando necessário, meios diagnósticos por imagem, como radiografias simples e contrastada, ultrassonografia e endoscopia. Os procedimentos utilizados para desobstrução do trato digestório incluíram a endoscopia, a remoção de CE esofágico próximo à faringe com auxílio de pinça de apreensão, gastrotomia, enterotomia e ressecção e anastomose intestinais.

Quando foi necessário o acesso cirúrgico ao abdômen, os pacientes receberam fluidoterapia intravenosa e antibioticoterapia pré-operatórias, escolhidas de acordo com cada caso. Rotineiramente, todo o trato gastrointestinal foi avaliado, após incisão ventral mediana, e a presença de obstruções e a viabilidade tissular foram analisadas. O segmento afetado foi exteriorizado, isolado por compressas e umedecido com soro fisiológico aquecido.

Gastrotomias foram realizadas em região hipovascularizada do estômago, escolhida entre as curvaturas maior e menor. A gastrorrafia foi efetuada com fio de ácido poliglicólico, utilizando-se dois padrões de sutura contínua invaginante. A enterotomia foi realizada na borda antimesentérica intestinal e a enterorrafia com fio de ácido poliglicólico, em padrão simples separado ou em padrão contínuo. As anastomoses intestinais também foram realizadas com o mesmo fio, em padrão simples separado. Apenas em um caso, foi utilizado fio categute cromado para enterotomia. Após os procedimentos cirúrgicos, o órgão abordado, exteriorizado, foi lavado e limpo com gaze embebida em solução salina estéril a 0,9\%, aquecida. Nos casos em que foi detectada presença de peritonite durante a cirurgia ou em que houve extravasamento de conteúdo intestinal, toda a cavidade abdominal foi lavada com solução salina estéril a $0,9 \%$, aquecida, que foi aspirada até a obtenção de líquido com característica límpida.

Apesar de recomendado a todos os proprietários para manterem seus animais internados para fluidoterapia 
intravenosa, esta recomendação nem sempre foi acatada e os pacientes foram levados para casa, recebendo, em consequência, fluidoterapia enquanto permaneceram no HVT-UFV, em média por quatro horas.

Após as cirurgias invasivas, os animais foram submetidos a jejum líquido e sólido por um período de 8 a 12 horas. Após esse período, água e dieta de mais fácil digestão foram instituídas, se o animal não apresentava vômito, durante dez dias. Em seguida, a ração foi reintroduzida de forma gradual.

Para todos os animais, foi prescrita antibioticoterapia pós-operatória, por períodos variando entre 7 e 30 dias de administração. Foram utilizados a ceftriaxona, ceftiofur, amoxicilina com clavulanato de potássio, ampicilina, enrofloxacina, metronidazol, cefazolina e cefalexina. Medicação analgésica à base de morfina e tramadol foi prescrita por um período de 3 a 5 dias.

As taxas de mortalidade foram calculadas, considerando-se o período de evolução da doença e a localização do corpo estranho. $\mathrm{O}$ cálculo realizado foi: $\mathrm{n}^{\circ}$ de óbitos $\mathrm{x}$ $100 / \mathrm{n}^{\circ}$ total de casos. Os grupos de casos foram separados da seguinte maneira: número de casos totais; número de casos com período de evolução do quadro clínico inferior a sete dias; número de casos com o período superior a sete dias; número de casos de CE de localização esofágica e número de casos nos quais os CEs localizavam-se no estômago e intestinos.

Foram realizados hemogramas completos (eritrograma, leucograma e contagem de plaquetas) com o sangue de 12 animais. Exames bioquímicos, dosando níveis de ureia, creatinina, enzimas hepáticas (alaninoaminotransferase, aspartatoaminotransferase), fosfatase alcalina, proteína plasmática total e glicose sanguínea, foram realizados em oito animais. A coleta do sangue e a análise das amostras foram realizadas no mesmo dia em que os animais foram admitidos no Hospital Veterinário, no período inicial de atendimento clínico, antes de qualquer conduta terapêutica. Como se trata de um estudo retrospectivo, em algumas fichas não constava a totalidade dos exames laboratoriais a serem analisados, por discordância do proprietário em realizá-los ou pela emergência da situação, ou, então, pela falta de lançamento de dados.

Foi considerado apenas o percentual das observações durante a análise descritiva dos dados, uma vez que este levantamento não possui um número significativo de casos para aplicação de estudos analíticos.

\section{RESULTADOS E DISCUSSÃO}

\section{Avaliação de espécie, raça, sexo $e$ idade dos animais}

Em uma população de 2.520 cães atendidos no HVTUFV, durante o período de estudo, 16 apresentaram qua- dro de obstrução por ingestão de CE, o que corresponde a uma prevalência de $0,6 \%$, um valor baixo, porém compatível com estudos de Gianella et al. (2009), que encontraram $0,67 \%$ entre os cães que avaliaram. A população felina, por sua vez, era constituída de 252 animais e com apenas um gato acometido, correspondendo a uma prevalência de $0,4 \%$, um valor ainda menor.

Um trabalho retrospectivo, abordando a presença de CE, realizado por Hayes (2009), relatou média de um gato para cada oito cães atendidos, indicando frequência $100 \%$ maior em relação aos casos de obstrução atendidos no HVT-UFV (um gato para cada 16 cães), mas ainda assim, um valor pequeno. Este resultado aponta para a falta de seletividade do cão em relação ao gato quanto à ingestão de alimentos. No entanto, também deve ser considerada a pequena casuística de atendimentos de animais da espécie felina no Hospital Veterinário da UFV, provavelmente pela menor população absoluta de gatos.

Quanto ao número de casos de ingestão de CE atendidos, as raças Poodle e Teckel foram as mais frequentes, conforme observado na Figura 1. Em um estudo realizado por Rodríguez-Alarcón et al. (2010), a raça Poodle foi estatisticamente considerada de alto risco para ingestão de CE. Porém, é importante ressaltar que dentre a população atendida no HVT-UFV, a raça Poodle é das mais frequentes, podendo este ser um dos motivos para a casuística observada.

Como a frequência de atendimentos de Teckels no HVTUFV não é elevada, acredita-se que essa raça pode apresentar predisposição para a ingestão de CE, uma vez que houve o mesmo número de casos de obstrução em Poodles e em Teckels, o que pode estar relacionado principalmente com o comportamento da raça, criada para farejar, perseguir, caçar e matar pequenos roedores. Entretanto, existem relatos (Michels et al., 1995; Sale \& Williams, 2006; Leib \& Sartor, 2008; Gianella et al., 2009) que afirmaram que embora qualquer raça possa se apresentar com um CE obstruindo o trato digestório, os cães de raças pequenas são mais acometidos, por causa do menor diâmetro de órgãos tubulares.

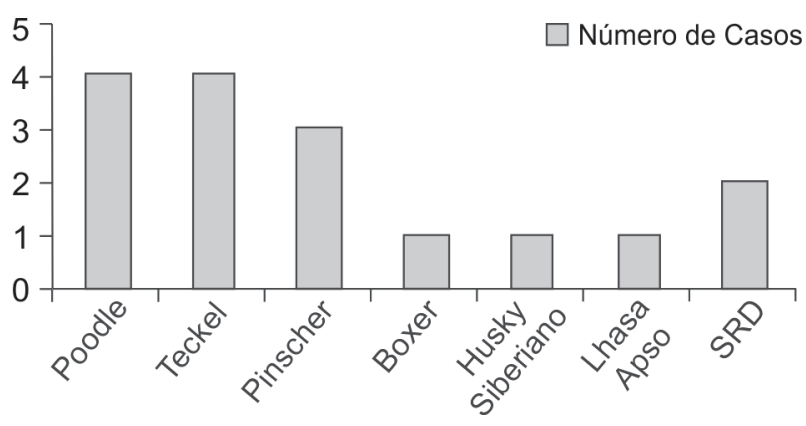

Figura 1. Relação de raças de cães atendidos no HVT-UFV com obstrução do trato digestório após ingestão de corpos estranhos. SRD: sem raça definida. 
Dos casos atendidos, $52,25 \%$ foram em fêmeas e 43,75\% em machos. Essa frequência maior, provavelmente, devese ao fato da população sabidamente maior de fêmeas, semelhante aos resultados encontrados em estudos prévios feitos por Boag et al. (2005) e Gianella et al. (2009).

A relação entre o número de casos de obstrução por ingestão de CE e a idade dos animais acometidos está listada na Tabela 1. Segundo Ellison (1998), a ingestão de CEé maior em animais jovens. Esta informação foi confirmada no presente estudo, pois cerca de $75 \%$ do total de animais acometidos tinham idade igual ou inferior a cinco anos. Boag et al. (2005) também encontraram resultados semelhantes, com maior acometimento de animais entre 1 e 5 anos e Hedlund \& Fossum (2007b) afirmaram que os CEs podem ocorrer em um animal de qualquer idade, porém, são mais comuns durante os três primeiros anos de vida, fato que, para Ellison (1998), está relacionado com o hábito de alimentação indiscriminada, principalmente, no caso de filhotes. Sugere-se que a ocorrência de CE em animais idosos, encontrada neste estudo, esteja relacionada com a perda do olfato e da falta de seletividade na ingestão do alimento.

\section{Tipos de corpos estranhos e sua localização}

A relação entre os tipos de $\mathrm{CE}$, o número de cães atendidos e o local da obstrução está apresentada na Tabela 1. Observa-se que os corpos estranhos estão relacionados com materiais que vêm sendo abolidos da alimentação de cães, no caso, os ossos, e também àqueles que são próprios da domesticação e coabitação com os seres humanos.

À semelhança do observado na Tabela 1, os autores da literatura compulsada (Twedt, 1995; Willard, 2006a; Hedlund \& Fossum, 2007b; Gianella et al., 2009) remetem a grande incidência de obstrução pela ingestão de ossos, permitindo inferir o quanto é inadequado este material na alimentação de caninos. Também, pode ser observado que os ossos foram sempre identificados como causa de obstrução esofágica, neste estudo. Acredita-se que os ossos que conseguem chegar ao estômago são digeridos, na maioria dos casos, sendo pouco observados como causa de obstrução gástrica ou intestinal.

Meias, panos e fios comportam-se da mesma forma, quando ingeridos. Há uma tendência de os primeiros desfazerem-se após adentrarem no estômago, uma extremidade fixa-se no piloro e o peristaltismo intestinal continua a movimentar a extremidade livre em direção ao intestino delgado, promovendo pregueamento das alças intestinais, conforme ilustrado nas imagens ultrassonográfica (A) e macroscópica (B) da Figura 2.

Alguns animais do estudo apresentaram quadro compatível com obstrução parcial do intestino e, à medida que o curso da doença prolongava-se, resultava na perda de funcionalidade de grandes porções de intestino, com sinais similares àqueles de obstrução completa. Nesses casos, a imagem radiográfica demonstrou alças intestinais e estômago distendidos e com presença de gases (Figura 2C). Dependendo da radiopacidade, o corpo estranho (Figura 2D) pode tornar-se visível ao exame radiográfico.

$\mathrm{Na}$ análise isolada do local da obstrução, observouse maior frequência de CEs gástricos e intestinais, 62,5\%, em relação aos CEs esofágicos, que representaram 37,5\% do total de casos. Twedt (1995) afirmou que a anatomia esofagiana permite maior distensão e dilatação que as alças intestinais e, desta forma, os CEs chegam com alguma facilidade ao estômago, mas ficam retidos no lúmen intestinal.

Notou-se também que o maior número de casos de obstruções em esôfago foi de localização cervical, apesar de Kyles (2003) justificar a ocorrência de CEs esofágicos nos pontos em que estruturas extraesofágicas limitam a dilatação do órgão. Desta forma, pode-se inferir que o que determina uma obstrução esofágica são as características do próprio corpo estranho, como forma e tamanho, em relação ao lúmen esofágico de cada animal.

Sete casos de obstrução por corpos estranhos foram classificados como lineares, correspondendo a $43,75 \%$ do total, número maior do que os 16 e $36 \%$ encontrados nos estudos retrospectivos de Hayes (2009) e Boag et al. (2005), respectivamente. Além disso, ambos os estudos basearam-se apenas em casos de CEs gástricos e intestinais, excluindo-se os esofágicos. Neste estudo, se fossem considerados apenas os CEs gástricos e intestinais, a percentagem de corpos estranhos lineares seria de $70 \%$.

Entre os CEs lineares, 62,5\% ancoravam-se no piloro, valor compatível com os $67 \%$ encontrados por Hayes (2009), sendo que alguns objetos encontrados não foram ingeridos como cordão, mas assumiram o formato linear após mastigação e digestão no estômago e avançaram pelo intestino delgado.

Segundo Papazoglou et al. (2003), os movimentos peristálticos continuam a mover o CE no sentido distal com resultante pregueamento do intestino delgado. Mas, em um caso, o corpo estranho linear fixou-se na transição jejuno-1́leo, enquanto a porção livre progrediu pelo cólon, envolvendo inclusive a válvula íleo-ceco-cólica, franzindo o intestino ao seu redor, com sintomatologia compatível com obstrução completa do intestino grosso. Desta forma, as obstruções do cólon não se restringem à obstrução concomitante do reto ou à presença de objetos pontiagudos, como citado por Hedlund \& Fossum (2007b).

\section{Procedimentos clínico-cirúrgicos}

Os tipos de procedimentos realizados para remoção dos CEs (Tabela 1) envolveram uma variedade grande de intervenções, que estiveram relacionadas com a peculiaridade do caso. 
Todos os corpos estranhos esofágicos foram retirados ou empurrados para o estômago por meio de endoscopia, conforme ilustrado na Figura 3A, ou foram removidos com uso de pinça de apreensão (nos casos de localização na porção cervical cranial do esôfago), não sendo necessária a realização de procedimento cirúrgico. Essas manobras puderam ser realizadas em vista do curto período de tempo decorrido entre a obstrução e o atendimento, limitando a progressão do CE.
A disponibilidade de um endoscópio flexível, além de favorecer a remoção satisfatória do CE, conforme recomendaram Willard (2006a), Hedlund \& Fossum (2007a) e Gianella et al. (2009), também permitiu a inspeção do lúmen esofágico após o procedimento, evidenciando lesões na parede do órgão, em todos os casos, conforme observado na Figura 3B.

Dois animais com CE esofágico vieram a óbito. Tratava-se de filhotes, cujos esôfagos estavam obstruídos por

Tabela 1. Relação entre idade, número de cães e identificação dos casos, relação entre os tipos de corpo estranho (CE), número de casos atendidos, local da obstrução e identificação dos casos e relação entre o tipo de procedimento realizado para remoção do corpo estranho, o número de casos atendidos e a identificação dos casos atendidos no HVT-UFV, com obstrução do trato digestório após ingestão de corpos estranhos

\begin{tabular}{lcc}
\hline & Relação idade, número de casos e identificação dos casos & \\
\hline Idade & $\mathbf{N}^{0}$ de casos & Identificação \\
\hline 2 meses & 1 & Caso 1 \\
6 meses & 1 & Caso 2 \\
7 meses & 1 & Caso 3 \\
11 meses & 1 & Caso 4 \\
12 meses & 3 & Casos 5, 6 e 7 \\
3 anos & 2 & Casos 8 e 9 \\
4 anos & 1 & Caso 10 \\
5 anos & 2 & Casos 11 e 12 \\
10 anos & 1 & Caso 13 \\
11 anos & 1 & Caso 14 \\
12 anos & 1 & Caso 15 \\
14 anos & 1 & Caso 16 \\
\hline
\end{tabular}

\begin{tabular}{|c|c|c|c|}
\hline \multicolumn{4}{|c|}{ Relação tipo de CE, local da obstrução, número de casos e identificação dos casos } \\
\hline Tipo de CE & Localização & $\mathrm{N}^{0}$ de casos & Identificação \\
\hline Osso & Esôfago Cervical & 3 & Casos 1,3 e 15 \\
\hline Não identificado* & Esôfago Cervical & 1 & Caso 16 \\
\hline Osso & Esôfago Próximo à base do coração & 1 & Caso 7 \\
\hline Osso & Esôfago Próximo à entrada do tórax & 1 & Caso 10 \\
\hline Plástico (corpo estranho linear) & Piloro, duodeno e jejuno & 2 & Casos 2 e 5 \\
\hline Meia (corpo estranho linear) & Piloro, duodeno e jejuno & 1 & Caso 6 \\
\hline Pano (corpo estranho linear) & Piloro e duodeno & 1 & Caso 9 \\
\hline Não identificado* (corpo estranho linear) & Piloro, duodeno e jejuno & 1 & Caso 4 \\
\hline Caroço de pêssego & Duodeno & 1 & Caso 11 \\
\hline Não identificado* & Jejuno & 1 & Caso 8 \\
\hline Meia & Jejuno-íleo & 1 & Caso 12 \\
\hline Fios (corpo estranho linear) & Jejuno-íleo & 1 & Caso 13 \\
\hline Meia (corpo estranho linear) & Jejuno -íleo-cólon & 1 & Caso 14 \\
\hline
\end{tabular}

Meia (corpo estranho linear)

Jejuno -íleo-cólon

Caso 14

Relação entre o tipo de procedimento realizado para remoção do corpo estranho, o número de casos atendidos e a identificação dos casos

\begin{tabular}{|c|c|c|}
\hline Procedimento & $\mathbf{N}^{0}$ de casos & Identificação \\
\hline Retirada com pinça de apreensão & 2 & Casos 1 e 3 \\
\hline Endoscopia esofágica & 3 & Casos $7,10,15$ \\
\hline Enterotomia única & 3 & Casos 8,11 e 12 \\
\hline Enterotomia múltipla & 3 & Casos 2,13 e 14 \\
\hline Gastrotomia e enterotomia & 1 & Caso 6 \\
\hline Gastrotomia, ressecção intestinal e enteranastomose & 1 & Caso 5 \\
\hline Gastrotomia, enterotomias, ressecção intestinal & 2 & Casos 4 e 9 \\
\hline
\end{tabular}

e enteranastomose

* Corpos estranhos cujo tipo não foi identificado nas fichas ou que o processo de digestão e necrose tissular associados impediram o reconhecimento do tipo de corpo estranho.

Rev. Ceres, Viçosa, v. 59, n.4, p. 434-445, jul/ago, 2012 
ossos grandes e pontiagudos, instalados na faringe. Ambos apresentavam sangramento esofágico antes de se tentar extrair o corpo estranho, indicando perfuração esofágica. Em um dos casos, o osso foi removido com sucesso, mas a lesão esofágica era extensa. No outro caso, o animal veio a óbito durante o procedimento de retirada do corpo estranho, que teve como complicação a extensão de ruptura esofágica pré-existente e de estruturas adjacentes, provocando sangramento intenso e morte por choque hipovolêmico. Há tendência, no órgão tubular, de espasmo sobre o corpo estranho, fragilizando a parede da víscera (Papazoglou et al., 2003), justificando o ocorrido.

Pela natureza do corpo estranho linear e sua tendência à fixação no piloro, as enterotomias que evidenciaram a presença do cordão tiveram que ser associadas a gastrotomias. Além disso, em três casos houve comprometimento da parede intestinal em vários sítios, resultando em peritonite localizada e fibrose intestinal, determinando plicatura permanente com áreas de necrose, conforme ilustra a Figura 3C e D, fazendo-se necessária a ressecção e anastomose, como recomendaram Ellison (1998) e Fossum \& Hedlund (2003).
Os corpos estranhos lineares exigiram, em seis casos atendidos, a realização de múltiplas enterotomias (Tabela 1), espaçadas ao longo do intestino, para minimizar a tração e evitar a subsequente perfuração intestinal e para permitir a completa remoção do $\mathrm{CE}$, pela extensão de alça atingida.

\section{Taxas de mortalidade}

O período entre a observação dos sinais, pelos proprietários, e o início do atendimento (período de evolução) variou de 1 a 30 dias (Tabela 2). Este dado refere-se a 15 animais, uma vez que um prontuário estava incompleto. Percebe-se que, em 73,4\% dos casos, os proprietários procuraram atendimento em até uma semana após a manifestação dos sintomas. Segundo Papazoglou et al. (2003), as manifestações por CE no sistema digestório e suas consequências são progressivas e postergar o atendimento pode ser comprometedor para o prognóstico.

A taxa de mortalidade geral de todos os casos de obstrução do trato digestório foi de $46,6 \%$; entretanto, o maior número de óbitos foi observado nos casos atendidos tardiamente. O período de evolução, em $26,6 \%$ dos casos, foi superior a sete dias. Notou-se que a taxa de mortalidade,

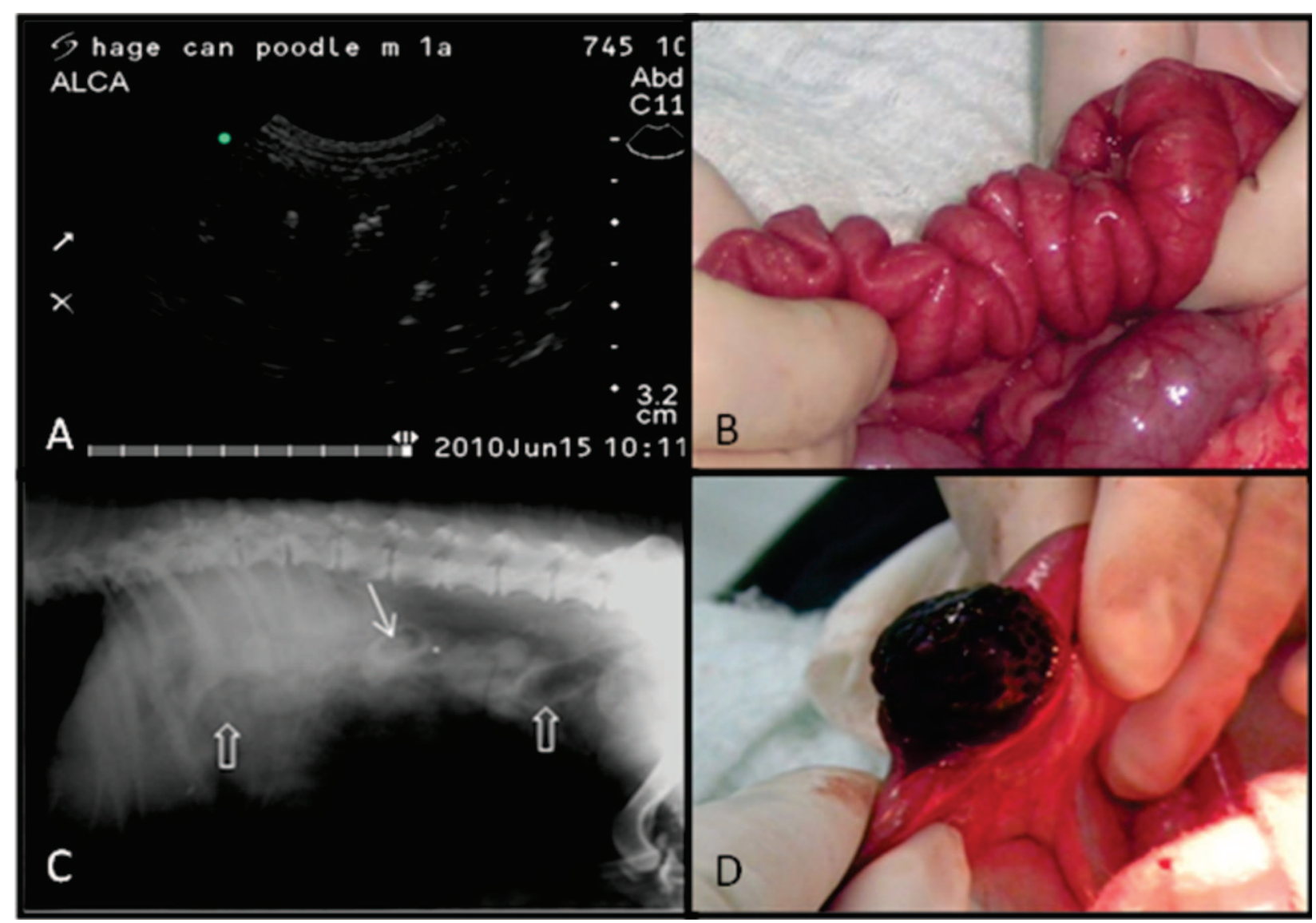

Figura 2. Obstrução intestinal por corpo estranho linear (caso 6) e obstrução completa de duodeno após ingestão de corpo estranho (caso 11). A. Imagem ultrassonográfica evidenciando pregueamento de alças intestinais consequente à ingestão de corpo estranho linear (caso 6). B. Fotografia de alças intestinais pregueadas à exploração cirúrgica (caso 6). C. Radiografia em projeção lateral do abdômen de cão, evidenciando alças intestinais e estômago distendidos e com gás (setas vazias) e estrutura radiopaca intestinal (seta) (caso 11). D. Caroço de pêssego provocando obstrução completa de duodeno (caso 11). Fonte: Arquivos HVT- UFV. 
relacionada com a manifestação dos sintomas em período de até sete dias, foi de $36,6 \%$, menor do que a observada nos animais com evolução clínica igual ou superior a sete dias (75\%). Conforme relatado por Papazoglou et al. (2003) e, independentemente da localização do corpo estranho, há tendência de o quadro se agravar à medida que transcorre o tempo, com risco de necrose, destruição da barreira mucosa, peritonite e septicemia, agravados pelos graus crescentes de desidratação e desequilíbrio eletrolítico.

A taxa de mortalidade para os pacientes portadores de CEs localizados no esôfago foi menor $(33,3 \%)$, quando comparada com as de ocorrência em estômago e intestinos $(55,5 \%)$, conforme evidenciado na Tabela 2. Essa menor taxa de mortalidade deveu-se a dois fatores: o primeiro foi o tipo de tratamento realizado, sem intervenção cirúrgica, que possui risco de deiscência de sutura amplamente reconhecido (Hedlund \& Fossum, 2007a) e, consequentemente, sem trauma operatório; o segundo motivo foi o fato de que animais portadores dessa afecção foram atendidos em até três dias, um período relativamente curto, com poucas alterações generalizadas e no tecido esofagiano. Já a remoção de CE de localização gástrica e intestinal requereu tratamento cirúrgico, demandando maior período de recuperação em paciente debilitado pelo processo mórbido primário, consequentemente ampliando a taxa de mortalidade.

A análise da Tabela 2 também evidenciou que, nos casos de obstrução gástrica e intestinal por CE, a taxa de mortalidade foi maior (75\%), quando a evolução do quadro clínico foi superior a sete dias. Casos de evolução inferiores a sete dias apresentaram taxa de 40\%. Apesar de Willard (2006b) enfatizar que a gravidade de uma obstrução intestinal depende do tipo (parcial ou total), do local (proximal ou distal) e da presença ou não de evento estrangulante, observou-se, neste estudo, que a demora no atendimento deve ser considerada.

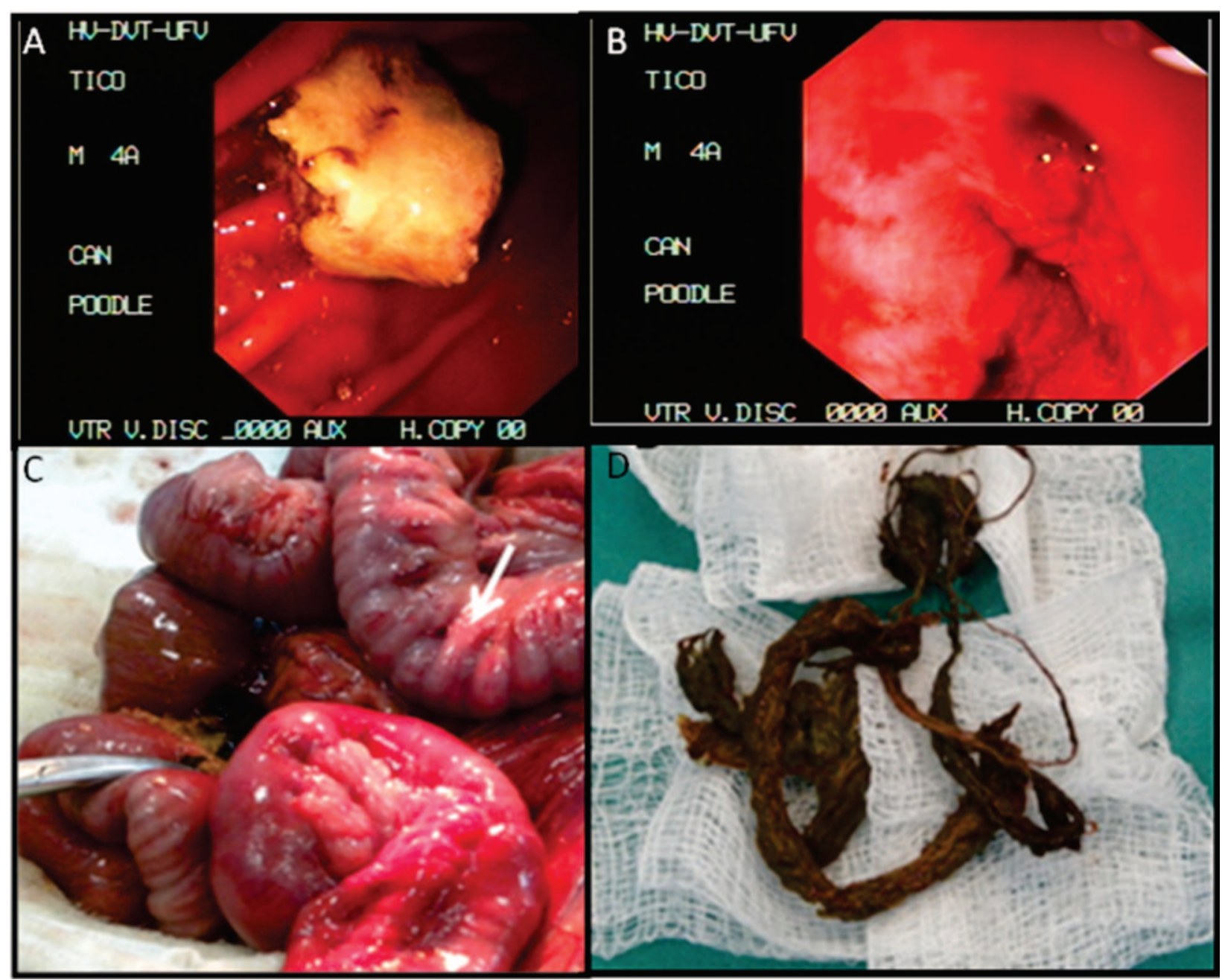

Figura 3. Imagens de endoscopia com obstrução esofágica após ingestão de corpo estranho (caso 10) e obstrução intestinal por corpo estranho linear (caso 13). A. Corpo estranho esofágico (osso) empurrado para o estômago (caso 10). B. Lesões na mucosa esofágica causadas pelo corpo estranho (caso 10). C. Alças intestinais pregueadas (seta) e ponto de ruptura em jejuno em cão (apontado com a pinça) por ação do corpo estranho linear (caso 13). D. Múltiplos fios retirados desde o piloro, duodeno e jejuno do cão (caso 13). Fonte: Arquivos HVT-UFV.

Rev. Ceres, Viçosa, v. 59, n.4, p. 434-445, jul/ago, 2012 
Os pacientes que foram atendidos após uma semana de início dos sinais clínicos apresentaram-se deprimidos, desidratados, com alterações eletrolíticas, com toxemia devida ou à proliferação bacteriana ou à liberação de toxinas, comprometendo seu estado geral e o resultado de procedimentos que foram utilizados. Também, e segundo Waxman (1996), a hipóxia tecidual afeta a função leucocitária, sugerindo que existem efeitos deletérios no sistema de defesa do hospedeiro, resultando em aumento da susceptibilidade à infecção e, consequentemente, maior risco de morte.

Ressalte-se que, nos casos cujo período de evolução do quadro foi maior, a demora no atendimento deveu-se à despreocupação do proprietário frente a quadros possivelmente mais simples, como em uma obstrução parcial. No entanto, o maior período de evolução fez com que alguns casos fossem agravados por necrose tissular, peritonite e desequilíbrio hidroeletrolítico, determinando as maiores taxas de mortalidade.

\section{Sintomatologia clínica}

Os sinais clínicos presentes nos animais portadores de obstrução esofágica, gástrica e intestinal após a ingestão de corpos estranhos estão descritos na Figura 4. Dentre os sintomas apresentados pelos portadores de CE esofágico citam-se, como mais frequentes, a apatia, hiporexia ou anorexia, regurgitação e dor à palpação. Apenas em um caso o animal apresentou tosse. Estes achados coincidiram com os relatados por Gianella et al. (2009) e Keir et al. (2010).

Em relação aos CEs gástricos e intestinais, os sintomas mais observados foram: apatia, hiporexia ou anorexia, vômito e dor à palpação abdominal. Nestes casos, a ingesta eliminada via oral tinha as características de vômito e o proprietário relatava esforços abdominais do animal prévios à eliminação do conteúdo, diferenciando-a da regurgitação observada após a ingestão do alimento e na presença da obstrução esofágica. As obstruções mais proximais, quando comparadas com a observada no íleo-

Tabela 2. Relação entre o tempo de evolução do quadro clínico, número de casos, número de óbitos e taxa de mortalidade e relação entre o tempo de evolução do quadro clínico, número de casos e identificação desses, número de óbitos e taxa de mortalidade em cães atendidos com obstrução do trato digestório após ingestão de corpos estranhos

\begin{tabular}{|c|c|c|c|c|c|}
\hline \multicolumn{6}{|c|}{ Tempo de evolução do quadro clínico, número de casos, número de óbitos e taxa de mortalidade } \\
\hline $\begin{array}{l}\text { Período evolução } \\
\text { (dias) }\end{array}$ & No de casos & $\mathrm{N}^{0}$ de óbitos & & $\begin{array}{c}\text { Taxa de } \\
\text { mortalidade }(\%)\end{array}$ & $\begin{array}{l}\text { Taxa de mortalidade } \\
\text { por período }(\%)\end{array}$ \\
\hline 1 & 3 & 2 & & 66 & \\
\hline 2 & 4 & 1 & & 25 & Até 7 dias \\
\hline 3 & 1 & 0 & & 0 & 36,6 \\
\hline 5 & 1 & 0 & & 0 & \\
\hline 6 & 1 & 0 & & 0 & \\
\hline 7 & 1 & 1 & & 100 & \\
\hline 15 & 3 & 2 & & 66 & Acima de 7 dias \\
\hline 30 & 1 & 1 & & 100 & 75 \\
\hline Total & 15 & 7 & & 46,66 & \\
\hline \multicolumn{6}{|c|}{ Tempo de evolução do quadro clínico, número de casos, número de óbitos e taxa de mortalidade } \\
\hline Dias de evolução & $\begin{array}{l}\text { Identificação } \\
\text { dos casos }\end{array}$ & $\mathrm{N}^{0}$ de casos & No de óbitos & $\begin{array}{c}\text { Taxa de } \\
\text { mortalidade }(\%)\end{array}$ & $\begin{array}{c}\text { Taxa de } \\
\text { mortalidade por } \\
\text { período }(\%)\end{array}$ \\
\hline \multicolumn{6}{|c|}{ Esôfago } \\
\hline 1 & Casos 1 e 7 & 2 & 1 & 50 & \\
\hline 2 & Casos 3,10 e 15 & 3 & 1 & 25 & 33,3 \\
\hline 3 & Caso 16 & 1 & 0 & 100 & \\
\hline \multicolumn{6}{|c|}{ Estômago e intestino } \\
\hline 1 & Caso 12 & 1 & 1 & 100 & \\
\hline 2 & Caso 2 & 1 & 0 & 0 & Até 7 dias \\
\hline 5 & Caso 14 & 1 & 0 & 0 & 40 \\
\hline 6 & Caso 13 & 1 & 0 & 0 & \\
\hline 7 & Caso 11 & 1 & 1 & 100 & \\
\hline 15 & Caso 5,6 e 9 & 3 & 2 & 66,6 & Acima de 7 dias \\
\hline 30 & Caso 4 & 1 & 1 & 100 & 75 \\
\hline Total & & 9 & 5 & 55,55 & \\
\hline
\end{tabular}


cólon, provocaram quadros mais frequentes de vômitos, com alterações clínicas mais agudas e severas, estando de acordo com o estabelecido na literatura (Twedt, 1995; Willard, 2006b; Hedlund \& Fossum, 2007b).

Seis animais atendidos $(37,5 \%)$ apresentaram, segundo seus proprietários, urina de coloração mais escura, de aspecto concentrado, e dois animais (12,5\%) apresentaram fezes ressecadas, que são sinais que acompanham a desidratação. Ressalte-se que os sintomas de apatia, anorexia, vômito/regurgitação, presentes na quase totalidade dos casos, foram inespecíficos, do ponto de vista do proprietário, e este fato pode ter sido uma das causas da demora em apresentar o animal para atendimento.

\section{Avaliações laboratoriais}

Os resultados das avaliações laboratoriais estão expressos na Tabela 3 e incluem valores referentes apenas a amostras de sangue de cães. Os valores de referência utilizados estão anexados à tabela e correspondem aos valores, segundo Thrall \& Weiser (2006), para hemograma, Kaneko et al. (2008), e o Manual de exames e serviços 2006/2007, do Instituto Hermes Pardini - Divisão Veterinária (2006/2007), para testes bioquímicos. A dosagem de proteína total foi incluída na Tabela 3, referente aos eritrogramas, para facilitar a interpretação destes em relação a quadros de desidratação.

Os resultados de eritrograma revelaram que três animais $(25 \%)$ apresentaram anemia arregenerativa, compatí- vel com inflamações de caráter crônico (Rich \& Coles, 1995), tal como o gerado pelos processos obstrutivos do trato alimentar. Essa anemia também poderia ser justificada por quadro de hemorragia no segmento do trato digestório obstruído. Um caso $(8,3 \%)$ apresentou anemia microcítica, compatível com deficiência de ferro. Os quadros obstrutivos crônicos podem acarretar maior permeabilidade vascular e perda sanguínea para o lúmen intestinal, com consequente perda de ferro. Além disso, algumas bactérias intestinais utilizam o ferro em seu metabolismo, promovendo sua redução no paciente.

O leucograma, por sua vez, revelou leucocitose, desvio à esquerda regenerativo, eosinopenia e linfopenia em $50 \%$ dos casos, condizentes com processos inflamatórios agudos, como nos casos de endotoxemia e infecção bacteriana aguda, que podem decorrer de um processo obstrutivo (Stockham et al., 2003), além de neutrofilia em $66,6 \%$ dos animais, também condizente com processos inflamatórios (Rich \& Coles, 1995). Um dos casos já apresentava contagem de linfócitos normal e monocitose acentuada, determinando maior cronicidade do processo inflamatório, conforme estudado por Stockham et al. (2003).

Quatro animais $(33,3 \%)$ apresentaram quadro de trombocitopenia discreta, que pode acontecer nos processos inflamatórios. No entanto, é importante ressaltar a elevada prevalência de Erlichiose Canina no HV/UFV, uma das principais causas de trombocitopenia (Stockham et al., 2003), embora seja, geralmente, mais acentuada nesses casos.

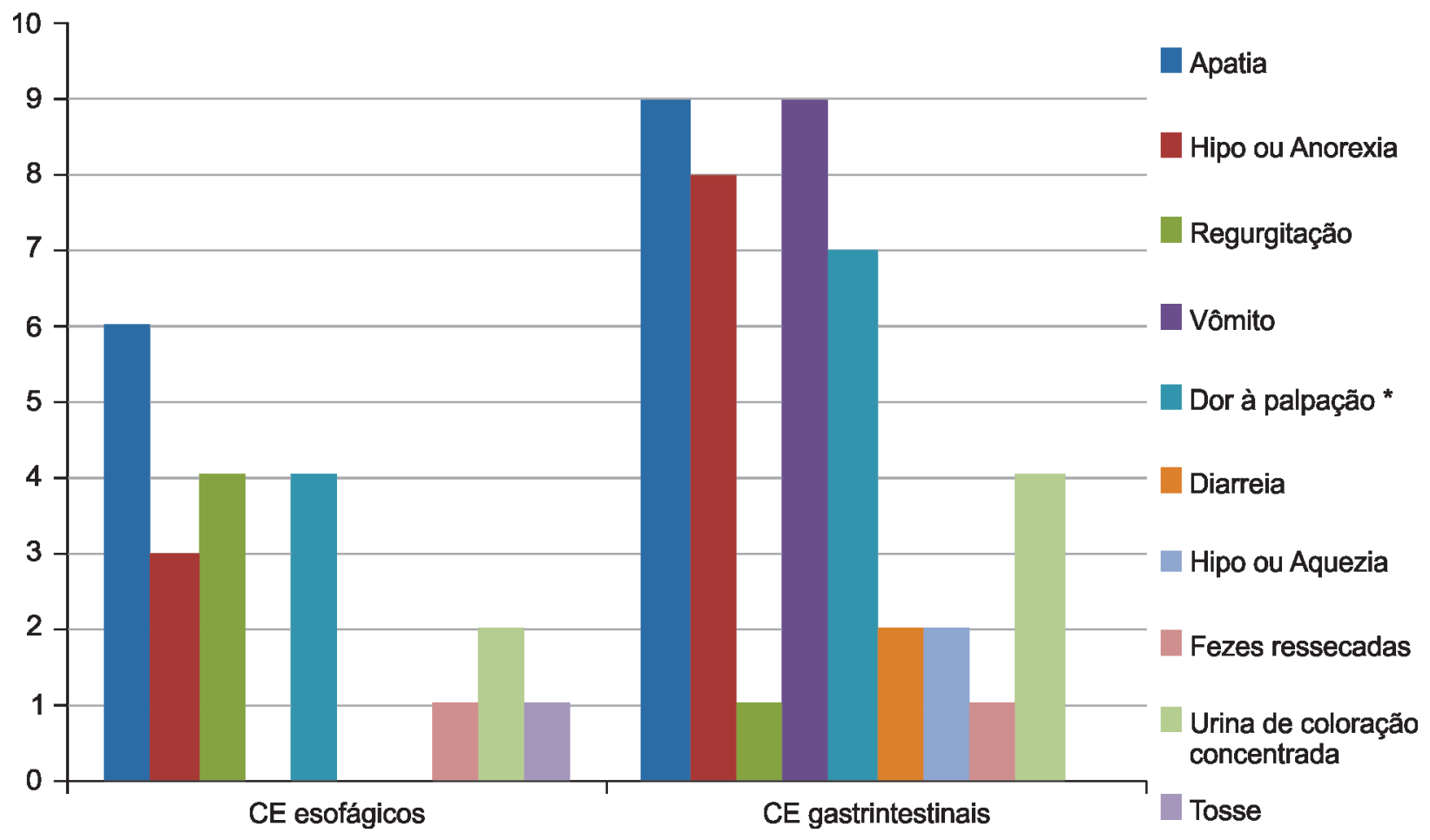

Figura 4. Relação entre o número de casos e os sinais clínicos presentes nos animais portadores de obstrução esofágica, gástrica e intestinal após a ingestão de corpos estranhos (CE). *Dor à palpação refere-se à região cervical ventral (se corpo estranho esofágico) e ao abdômen (se corpo estranho gastrointestinal). 
Os resultados dos exames bioquímicos revelaram aumento dos níveis de ureia em três animais $(37,5 \%)$, provavelmente por causa do quadro de desidratação, e aumento dos níveis de fosfatase alcalina em cinco animais
$(62,5 \%)$, condizentes com quadro de septicemia, desenvolvido a partir do processo obstrutivo, com o aumento da permeabilidade vascular e maior circulação de leucócitos contendo bactérias da região acometida.

Tabela 3. Valores observados para eritrograma, leucograma e bioquímica sérica nos animais portadores de obstrução esofágica, gástrica e intestinal após a ingestão de corpos estranhos, e sua relação com o óbito do paciente

\begin{tabular}{|c|c|c|c|c|c|c|c|c|}
\hline \multicolumn{9}{|c|}{ Valores para eritrograma } \\
\hline IC & Hem./ $\mu \mathrm{L}$ & $\begin{array}{l}\text { Hgl. } \\
\text { (g/dL) }\end{array}$ & $\begin{array}{l}\text { HT } \\
(\%)\end{array}$ & $\begin{array}{c}\text { VGM } \\
\text { (fL) }\end{array}$ & $\begin{array}{l}\text { HGM } \\
(\mathrm{pg})\end{array}$ & $\begin{array}{c}\text { CHGM } \\
(\mathrm{g} / \mathrm{dL})\end{array}$ & $\begin{array}{c}\text { PT } \\
(\mathrm{g} / \mathrm{dL})\end{array}$ & $\begin{array}{c}\text { Óbito } \\
\text { do paciente }\end{array}$ \\
\hline $\begin{array}{l}\text { Caso } 1 \\
\text { n }\end{array}$ & $5,74 \times 10^{6}$ & 13,2 & 38 & 66 & 23 & 34,7 & 6,1 & $\operatorname{sim}$ \\
\hline Caso 8 & $8,25 \times 10^{6}$ & $18,3^{*}$ & $56,4^{*}$ & 68 & 22,2 & 32,4 & 6,6 & $\operatorname{sim}$ \\
\hline Caso 5 & $4,7 \times 10^{6 *}$ & 13,6 & 37,2 & $78 *$ & $28,9 *$ & $36,4 *$ & 7 & $\operatorname{sim}$ \\
\hline Caso 4 & $2,34 \times 10^{6 *}$ & $6,1 *$ & $18,2 *$ & $78 *$ & $25,9 *$ & 33,2 & $4,8^{*}$ & $\operatorname{sim}$ \\
\hline Caso 3 & $3,95 \times 10^{6 *}$ & $8,7 *$ & $26,6^{*}$ & 67 & 21,9 & 32,6 & 6,4 & $\operatorname{sim}$ \\
\hline Caso 6 & $8,74 \times 10^{6}$ & $20,5^{*}$ & $60,7 *$ & 69 & $23,5^{*}$ & 33,8 & $9 *$ & não \\
\hline Caso 10 & $6,87 \times 10^{6}$ & 16,6 & 47,9 & 70 & $24,2 *$ & 34,7 & $8 *$ & não \\
\hline Caso 12 & $6,54 \times 10^{6}$ & 14,7 & 45 & 69 & 22,5 & 32,6 & 6,4 & não \\
\hline Caso 13 & $6,82 \times 10^{6}$ & 17,7 & 44,4 & 65 & $26^{*}$ & $39,9 *$ & $8,4^{*}$ & não \\
\hline Caso 7 & $6,87 \times 10^{6}$ & 13,7 & 43,4 & 63 & 19,9 & $31,4^{*}$ & 6,1 & não \\
\hline Caso 9 & $6,02 \times 10^{6}$ & $10^{*}$ & $29 *$ & $48 *$ & $16,6^{*}$ & 34,5 & $5,4^{*}$ & não \\
\hline Caso 14 & $5,82 \times 10^{6}$ & 13,2 & 37,8 & 65 & 22,6 & $38,8^{*}$ & $9,6^{*}$ & não \\
\hline $\begin{array}{l}\text { Valor de } \\
\text { referência }\end{array}$ & $5,5-8,5 \times 10^{6}$ & $12-18$ & $37-55$ & $60-77$ & $19-23$ & $32-36$ & $6-7,5$ & \\
\hline
\end{tabular}

\begin{tabular}{|c|c|c|c|c|c|c|c|c|}
\hline \multicolumn{9}{|c|}{ Valores para leucograma } \\
\hline $\mathrm{IC}$ & $\mathrm{LT} / \mu \mathrm{L}$ & Eos. $/ \mu \mathrm{L}$ & Bast. $/ \mu \mathrm{L}$ & Seg. $/ \mu \mathrm{L}$ & Linf. $/ \mu \mathrm{L}$ & Mon. $/ \mu \mathrm{L}$ & PLT/ $/ \mathrm{L}$ & Óbito \\
\hline Caso 1 & 11600 & 116 & 464 & 7424 & 2668 & 928 & 254000 & $\operatorname{sim}$ \\
\hline Caso 8 & $18000 *$ & $0 *$ & $2160 * *$ & $11700 *$ & $720 *$ & 540 & 352000 & $\operatorname{sim}$ \\
\hline Caso 5 & $23900 *$ & 1195 & $717 * *$ & $16881^{*}$ & 1434 & 1673 & $194000 *$ & $\operatorname{sim}$ \\
\hline Caso 4 & $27300 *$ & $0 *$ & $2457 * *$ & $19110^{*}$ & 3003 & 2730 & 201000 & $\operatorname{sim}$ \\
\hline Caso 3 & 15600 & 1092 & $6084 * *$ & 6864 & $624 *$ & 936 & $136000^{*}$ & $\operatorname{sim}$ \\
\hline Caso 6 & 14400 & 144 & 288 & $12816^{*}$ & $576^{*}$ & 576 & 375000 & não \\
\hline Caso 10 & 11100 & 333 & 111 & 8880 & $666^{*}$ & 1110 & 201000 & não \\
\hline Caso 12 & 9700 & $0 *$ & 194 & 6536 & $388^{*}$ & 582 & $188000^{*}$ & não \\
\hline Caso 13 & $24400 * *$ & $0 *$ & $2684 * *$ & $20008^{*}$ & $732 *$ & 976 & 326000 & não \\
\hline Caso 7 & 16200 & 648 & 324 & $12312 *$ & 1782 & 1134 & 415000 & não \\
\hline Caso 9 & $19800 * *$ & $0 *$ & 198 & $17424 *$ & 1584 & 594 & 538000 & não \\
\hline Caso 14 & $27100 * *$ & $0 *$ & $3523 * *$ & $17886^{*}$ & 1626 & $4065 * *$ & 272000 & não \\
\hline $\begin{array}{l}\text { Valor de } \\
\text { referência }\end{array}$ & $6-17 \times 10^{3}$ & $100-1250$ & $0-500$ & $3-11,5 \times 10^{3}$ & $1000-4800$ & $150-1350$ & $2-9 \times 10^{5}$ & \\
\hline \multicolumn{9}{|c|}{ Valores para bioquímica sérica } \\
\hline IC & $\begin{array}{c}\text { Ureia } \\
(\mathrm{mg} / \mathrm{dL})\end{array}$ & $\begin{array}{l}\text { Creat. } \\
(\mathrm{mg} / \mathrm{dL})\end{array}$ & $\begin{array}{l}\text { ALT } \\
(\mathbf{U} / \mathbf{L})\end{array}$ & $\begin{array}{l}\mathbf{A S T} \\
(\mathbf{U} / \mathbf{L})\end{array}$ & $\begin{array}{c}\text { FA } \\
(\mathbf{U} / \mathbf{L})\end{array}$ & $\begin{array}{l}\text { Glicose } \\
(\mathrm{mg} / \mathrm{dL})\end{array}$ & $\begin{array}{c}\text { Óbito } \\
\text { do paciente }\end{array}$ & \\
\hline Caso 8 & 58,78 & 0,9 & 27 & 34 & 83 & 59,34* & $\operatorname{sim}$ & \\
\hline Caso 5 & $76,4^{*}$ & $2,2 * *$ & 38 & 27 & $283 * *$ & 110,3 & $\operatorname{sim}$ & \\
\hline Caso 3 & $71,1 *$ & 0,6 & 17 & 27 & $248 * *$ & 97,2 & $\operatorname{sim}$ & \\
\hline Caso 6 & $242 *$ & $2 * *$ & 31 & 24 & 99 & $132 * *$ & não & \\
\hline Caso 12 & 40,8 & 0,7 & 68 & 54 & 91 & 95,33 & não & \\
\hline Caso 13 & 51,06 & 0,7 & 34 & $87 * *$ & $464 * *$ & 91,3 & não & \\
\hline Caso 7 & 23,91 & 0,6 & 34 & 62 & $204 * *$ & $36,81^{*}$ & não & \\
\hline Caso 14 & 39 & 0,7 & 10 & $10 *$ & $415^{* *}$ & $129,31 *$ & não & \\
\hline $\begin{array}{l}\text { Valor de } \\
\text { referência }\end{array}$ & $10-60$ & $0,5-1,6$ & $7-72$ & $23-66$ & $20-156$ & $65-118$ & & \\
\hline
\end{tabular}

Legenda: IC: identificação dos casos; Hem: número de hemácias; Hgl: quantidade de hemoglobina; HT: hematócrio; VGM: volume globular médio; HGM: hemoglobina globular média; CHGM: concentração de hemoglobina globular média; PT: proteína total; LT: leucócitos totais; Eos: eosinófilos; Bast: bastonetes; Seg: segmentados; Linf: linfócitos; Mon: monócitos; PLT: plaquetas; Creat: creatinina; ALT: alanina aminotransferase; AST: aspartato aminotransferase; FA: fosfatase alcalina. Os valores abaixo do de referência encontram-se com um asterisco e os valores acima do de referência apresentam dois asteriscos ao lado. 
Dois animais $(16,6 \%)$ apresentaram quadro de hipoproteinemia, sugestivo de hipoalbuminemia, que pode ter acontecido por causa do aumento da permeabilidade vascular, má absorção intestinal e redução da ingestão proteica na alimentação, uma vez que a maioria dos animais demonstrava hiporexia ou anorexia. Quatro animais $(33,3 \%)$ apresentaram quadro de hiperproteinemia, sugestivos tanto de um quadro de desidratação, como de possível aumento de globulina, como resposta ao processo inflamatório causado pela obstrução. Um animal (12,5\%) apresentou aumento discreto de creatinina, sugestivo de comprometimento renal inicial, explicado por quadro de septicemia e início de falência orgânica. Dois animais apresentaram-se hipoglicêmicos. Os animais com quadros obstrutivos, como visto anteriormente, apresentavam-se hiporéxicos ou anoréxicos, em sua maioria, podendo-se então determinar a redução dos níveis séricos de glicose. Dois animais $(25 \%)$ apresentaram aumento discreto da glicemia, sem explicação aparente.

Considere-se, também, que outras enfermidades podem causar os mesmos achados laboratoriais, como parasitismo intestinal, espoliação sanguínea por ectoparasitas ou hemoparasitoses, determinando anemia, e qualquer outro processo infeccioso bacteriano sistêmico, causador de alterações leucocitárias. Em consequência disso, não foi possível afirmar a existência de associação fidedigna entre os resultados encontrados e os quadros obstrutivos, assim como não houve relação entre as alterações laboratoriais e os óbitos observados, uma vez que alguns animais com alterações nos exames sobreviveram e outros, sem alterações, vieram a óbito. Ressalte-se também que todas as alterações mencionadas ocorreram em casos de obstrução gástrica e intestinal, a exceção de um caso, com obstrução esofágica, o que considera a ideia de maior gravidade dos processos obstrutivos em estômago e intestinos.

\section{CONCLUSÕES}

Este estudo demonstrou que as raças de porte pequeno são mais predisponentes a apresentar obstrução por ingestão de corpo estranho, evidenciando maior risco em cães da raça Teckel. O sexo não é fator interferente e a faixa etária envolvendo os animais mais jovens é a mais acometida. Ossos são encontrados principalmente obstruindo o esôfago, sendo pouco relevantes como causa de obstrução gástrica ou intestinal. Corpos estranhos do tipo linear foram encontrados em estômago e intestinos, ancorando-se especialmente em região de piloro.

O maior número de corpos estranhos encontra-se em estômago e intestinos, com maior gravidade e elevada taxa de mortalidade em relação aos esofágicos. A demora do atendimento contribui para maiores taxas de mortalidade. A sintomatologia clínica dos animais é diversa e inespecífica e quadros de apatia e anorexia ocorrem na maioria dos casos. Regurgitação e vômito são frequentes, em casos cuja localização do corpo estranho é esofágica e gastrointestinal, respectivamente. Os exames laboratoriais são, em geral, inespecíficos, e nem sempre as alterações encontradas relacionam-se ao mau prognóstico do paciente.

\section{REFERÊNCIAS}

Boag AK, Coe RJ, Martinez TA \& Hughes D (2005) Acid-base and electrolyte abnormalities in dogs with gastrointestinal foreign bodies. Journal of Veterinary Internal Medicine, 19:816-821.

Ellison GW (1998) Enterotomy. In: Bojrab MJ (Ed.) Current techniques in small animal surgery. Maryland, Williams \& Wilkins. p.245-276.

Fossum TW \& Hedlund CS (2003) Gastric and intestinal surgery. Veterinary Clinical Small Animal Practice, 33:1117-1145.

Gianella P, Pfammatter NS \& Burgener IA (2009) Oesophageal and gastric endoscopic foreign body removal: Complications and follow-up of 102 dogs. Journal of Small Animal Practice, 50:649-654

Hayes G (2009) Gastrointestinal foreign bodies in dogs and cats: A retrospective study of 208 cases. Journal of Small Animal Practice, 50:576-583.

Hedlund CS \& Fossum TW (2007a) Surgery of the esophagus. In: Fossum TW (Ed.) Small animal surgery. Missouri, Elsevier. p.384-389.

Hedlund CS \& Fossum TW (2007b) Surgery of the small intestine. In: Fossum TW (Ed.) Small animal surgery. Missouri, Elsevier. p.462-466.

Instituto Hermes Pardini - Divisão Veterinária (2006/2007) Manual de exames e serviços. Disponível em: <http:// www.hermespardini.com.br/docs/Manualdeveterinaria_20062007.pdf>. Acessado em: 02 de fevereiro de 2011.

Kaneko JJ, Harvey JW \& Bruss ML (2008) Blood analyte reference values in small and some laboratory animals. In: Kaneko JJ, Harvey JW \& Bruss ML (Eds.) Clinical biochemistry of domestic animals. Burlington, Elsevier. p.889-895.

Keir I, Woolford L, Hirst C \& Adamantos S (2010) Fatal aortic oesophageal fistula following oesophageal foreign body removal in a dog. Journal of Small Animal Practice, 51:657-660.

Kyles AE (2003) Esophagus. In: Slatter D (Ed.) Textbook of small animal surgery. Philadelphia, Elsevier Science. p.573-591.

Leib MS \& Sartor LL (2008) Esophageal foreign body obstruction caused by a dental chew treat in 31 dogs (2000-2006). Journal of American Veterinary Medical Association, 232:1021-1025.

Michels GM, Jones BD, Huss BT \& Wagner-Mann C (1995) Endoscopic and surgical retrieval of fishhooks from the stomach and esophagus in dogs and cats: 75 cases (1977-1993). Journal American Veterinary Medical Association, 207:1194-1197.

Papazoglou LG, Patsikas MN \& Rallis T (2003) Intestinal foreign bodies in dogs and cats. Compedium Continued Education Practice Veterinary, 25:830-843.

Parker NR, Walter PA \& Gay J (1989) Diagnosis and surgical management of esophageal perforation. Journal American Animal Hospital Association, 25:587-594. 
Rich LG \& Coles EH (1995) Tables of abnormal values as a guide to disease syndromes. In: Ettinger SJ \& Feldman EC (Eds.) Textbook of veterinary internal medicine. $4^{\mathrm{a}}$ ed. Philadelphia, Sauders Company. p.11-17.

Rodríguez-Alarcón CA, Usón J, Beristain DM, Rivera R \& Andrés $\mathrm{S}$ (2010) Breed as risk factor for esophagealforeign bodies. Journal of Small Animal Practice, 51:357.

Sale CS \& Williams JM (2006) Results of transthoracic esophagotomy retrieval of esophageal foreign body obstructions in dogs: 14 cases (2000-2004). Journal American Animal Hospital Association, 42:450-445.

Stockham SL, Keeton LS \& Szladovits B (2003) Clinical assessment of leukocytosis: distinguishing leukocytosis caused by inflammatory, glucocorticoid, physiologic, and leukemic disorders or conditions. Veterinary Clinical Small Animal, $33: 1335-1357$.
Thrall MA \& Weiser MG (2006) Hematologia. In: Hendrix CM (Ed.) Procedimentos laboratoriais para técnicos veterinários. São Paulo, Roca. p.31-78.

Twedt DC (1995) Diseases of the esophagus. In: Ettinger SJ \& Feldman EC (Eds.) Textbook of veterinary internal medicine. Philadelphia, Sauders Company. p.1124-1142.

Waxman K (1996) Shock: ischemia, reperfusion and inflamation. Critical Care Medicine, 4:153-160.

Willard MD (2006a) Distúrbios da cavidade oral, faringe e esôfago. In: Nelson RW \& Couto CG (Eds.) Medicina interna de pequenos animais. Rio de Janeiro, Elsevier. p.401-402.

Willard MD (2006b) Disúrbios do trato intestinal. In: Nelson RW \& Couto CG (Eds.) Medicina interna de pequenos animais. Rio de Janeiro, Elsevier. p.436-444. 